\section{Nature of chiral drugs and their occurrence in environment}

\section{Bhavtosh Sharma \\ Uttarakhand Science Education \& Research Centre, Dehradun, India}

\begin{abstract}
Effectiveness of chiral drugs is very well established against several lethal diseases. The demand of chiral drugs is increasing day by day. Besides this, the racemization of some chiral drugs is also found in biological as well as in environmental matrices. The analysis of chiral drugs has become a necessary Research and Development Unit task for any analytical scientist, pharmaceutical institute or pharma industry considering not only the specific role of these drugs for better and suitable treatment of any lethal disease but also for their occurrence and fate in environmental matrices. The present article highlights the importance, bioactivities, occurrence and fate of chiral drugs in environment.
\end{abstract}

\section{Introduction}

Any object which forms non-superimposable mirror images and is deficient with symmetry elements is known as chiral object. All amino acids, proteins, enzymes, carbohydrates etc. are chiral compounds in nature. Initially, Louis Pasteur discovered the chiral chemistry in 1948 during the separation of two isomers of sodium ammonium tartrate. ${ }^{1}$ Though, chirality possesses a key role not only in the existence of living beings such as plants and animals but in pharmaceutical and other chemical industries. Most of the pharmaceutical compounds show the optical activity due to their asymmetric nature. Now it has been established that only one of the two enantiomers i.e. eutomer is pharmacologically active while its counterpart i.e. distomer generally creates side effects or toxic effects or may inert. The significant biological activities of enantiomers of drugs have created an interest of scientific community to study their pharmacological and toxicological effects. $^{2-5}$ Therefore, the administration of pharmacologically active enantiomer of drug possesses specific importance. Moreover, the United States Food and Drug Administration (US FDA), European Committee for Proprietary Medicinal Products and other drug controlling agencies have issued definite guidelines to pharmaceutical industries regarding the marketing of these racemic compounds. ${ }^{6,7}$ Now after 1992 FDA and 1994 EU guidelines, the pharmaceutical industries are moving from racemates to single enantiomers. $^{8-10}$ Therefore, the enantiomeric resolution of the chiral compounds has now become an urgent need. As it has been established that human body is highly chiral selective and will interact differently with a racemic drug. Moreover, human body metabolizes each drug enantiomer by a different route with different pharmacological activity because the enantiomer of a drug possesses distinct biological interactions and therefore different pharmacological activities. Therefore, chirality has now become an essential part in research and development of drugs. The separation and testing of the enantiomeric forms of chiral drugs have become necessary due to their different potential, toxicity and nature in biological system as well as in environmental samples. The research and development task for chiral drugs is being done by scientists and researchers considering the several different issues associated with drug or its enantiomer like its racemic nature, enantiomeric synthesis, analysis or resolution, dosage potential, side effects, inactiveness in the biological system. While on the other hand some chiral drugs like thalidomide, ibuprofen etc. are also reported in different environmental matrices. ${ }^{11-15}$

Currently, the growing attention is being given for the development of effective chiral resolution methods, controlled enantioselective chemical synthesis, determination of enantiomeric purity and pharmacodynamics. Various techniques especially chiral chromatographic methods have been developed. Besides, capillary zone electrophoresis, capillary gel electrophoresis and capillary electrochromatography have been established as powerful tools over chromatographic techniques for enantiomeric analytical studies in environmental and biological samples both. Consumption of pharmaceuticals has increased not only due to increasing human population but also due to the application of these compounds to prevent the fatal diseases in livestock. Diclofenac, aceclofenac, acetaminofen and meloxicam drugs have been used as non-steroidal anti inflammatory drugs in livestock. Some fetal diseases of livestock like respiratory diseases, swine dysentery, and bacterial enteritis are being treated by using several pharmaceuticals. Besides this, antimicrobial drugs are also used in livestock. ${ }^{16}$ Moreover, as per a US Department of Agriculture (USDA)'s survey of 2010, it is estimated that approximately $80 \%$ of breeder chicken farms in United States vaccinated pullets in opposition to Salmonella, bronchitis, and coccidiosis, among other fetal diseases. ${ }^{17}$

Besides, the drugs and pharmaceuticals are being introduced in to the environment through
Correspondence: Bhavtosh Sharma,

Uttarakhand Science Education \& Research Centre (USERC), 33/2 Vasant Vihar, Dehradun, Uttarakhand, India.

Tel.: +91.135.2760297.

E-mail: bhavtoshchem@gmail.com

Key words: chiral drug, racemization, analysis, environment.

Acknowledgements: the author is thankful to the Director USERC for providing the necessary facilities to complete this work.

Conflict of interests: the author declares no potential conflict of interests

Received for publication: 9 February 2014.

Revision received: 8 April 2014.

Accepted for publication: 24 April 2014.

This work is licensed under a Creative Commons Attribution NonCommercial 3.0 License (CC BYNC 3.0).

(C) Copyright B. Sharma, 2014

Licensee PAGEPress, Italy

Journal of Xenobiotics 2014; 4:2272

doi:10.4081/xeno.2014.2272

human excretion as unmetabolized fractions, as untreated waste from sewage treatment plants or due to less efficiency of sewage treatment plant (STP), etc. Kasprzyk-Hordern and Baker have studied the enantiomeric-specific fate of many chiral drugs such as amphetamine, meta-amphetamine, ephedrine, pseudoephedrine, atenolol, vanlafaxine during waste water treatment and also in receiving water body. The authors also reported that the stereoselectivity depends on the type of chiral drug, used technology and seasons. These facts clearly indicate the less efficiencies of STPs. ${ }^{18}$ The occurrence of Ibuprofen enantiomeric composition in surface water and waste water treatment plants using enantioselective gas chromatography-mass spectrometric method. ${ }^{14}$ The authors found that ibuprofen and its metabolites were degraded up to $95 \%$ but the rate of degradation of clofibric acid and diclofenac was found very less during the treatment process due to the less efficiency of waste water treatment plants (WWTPs) for these drugs. ${ }^{14}$ The occurrence of drugs and pharmaceuticals as well as their metabolites in municipal waste water and finally in to aquatic system has become a serious problem not only for aquatic organisms but for humans also. ${ }^{19}$ The impact of pharmaceuticals on the environment has been studied very less where as these compounds are very hazardous for aquatic environment and introduced in to the environment through various routes. ${ }^{20}$ Therefore, the present article highlights the fate and occurrence of chiral pharmaceuticals in environmental matrices. 


\section{Global chiral drug market}

At present about $60-70 \%$ pharmaceuticals are chiral drugs. The international market of chiral synthesis, chiral analysis and chiral resolution is rising rapidly. However, according to a report, the Global Market of Chiral Technology was $\$ 5.3$ billion during 2011 year and will come up to $\$ 7.2$ billion approximately at the end of year 2016. ${ }^{21}$ This statistics of chiral market is sufficient to understand the fact that the awareness about the importance of chiral drug application is ever-increasing. Although pharma industries possess the major part in global chiral market but biochemical, agrochemical, food and flavor industries are also adopting chiral technologies. Therefore, the chiral products either drugs, pharmaceuticals, agrochemicals or chiral technologies have become the need of the time and their demand is increasing in the light of its potential importance and public welfare.

\section{Important chiral drug enantiomers and their bioactivities}

Several studies have reported that chiral drug stereoisomers generally represent clear differences in their metabolic and pharmacokinetic activities. ${ }^{22,23}$ Some of the important chiral drug enantiomers and their properties specially bioactivities are given in Table $1 .^{6,7,24}$

\section{Chiral drugs in environment}

Chiral drug enantiomers are boon for a lethal disease but there are some examples that one of the enantiomer of these drugs is toxic and termed as chiral pollutant. Despite the above facts, the degradation of achiral drugs or pollutants can be changed into toxic metabolites or intermediate compounds under various environmental conditions through various kinetic or thermodynamic parameters. However, it has been established that the degradation of these compounds take place in environment either by chemically or biologically at different rates. Generally, chiral xenobiotics occur in dynamic equilibrium in a water body with sediments. Dynamic equilibrium of chiral drugs in environment means a system with a steady state if the forward and backward reactions proceed at the same rate. Due to the dynamic equilibrium of chiral drugs in environment, these chemical species exist in more than one form.

The origin of chiral xenobiotics in environ- ment may be point i.e. through domestic or industrial activities or may be non-point i.e. through agricultural activities etc. Hegeman and Lanne ${ }^{25}$ have discussed the distribution pattern of chiral xenobiotics in environmental ecosystem. Some research work has been carried out by researchers to understand the environmental fate and toxicity of pharmacologically active compound of used drugs and pharmaceuticals in environment especially chiral drugs. The enantiomers of chiral drugs can be different in their toxic nature because of their different pharmacological activity. Besides, the degradation of chiral drugs in environment as well as in waste water treatment process can be stereoselective and various chiral products of different toxicity can be formed. Although the studies on the occurrence and fate of drugs are very limited ${ }^{26-31}$ but their presence in the environment can not be neglected. ${ }^{32}$

Many of the chiral drug compounds have been occurred in water resources such as in river water, lakes, oceans and in ground water system also. ${ }^{33-35}$ Besides, the occurrence of these compounds has been established in sediments and soil systems also by several researchers. ${ }^{36-40}$ Now a days, several chiral compounds have been detected in several vegetables, crops and in some other food products. ${ }^{41,42}$ Antibiotics, steroids, analgesic drugs are the most commonly studied pharmaceuticals. Antiinflammatories i.e. diclofenac, ibuprofen, naproxen, ketoprofen, blood lipid regulators and their metabolites have been recently reported as toxic in respect of certain bacteria and algae. ${ }^{43}$ Carbamazepine drug has been widely detected in the environment. ${ }^{26,28}$ Basically, municipal effluents are the principal sources of these pollutants. ${ }^{44-51}$ The conventional WWTPs are not sufficiently able to treat municipal effluents due to the hydrophilic nature of these compounds. However, emerging contaminants and their transformation products have been recognized by advanced analytical tools such as liquid chromatography (LC) or gas chromatography (GC) in association with tandem mass spectrometric (MS/MS) detection. ${ }^{52}$ Further in another research, some $\beta$-blockers (viz. atenolol, metoprolol, propranolol, pindolol, nadolol and sotalol), selective serotonin reuptake inhibitors (citalopram and fluoxetine) and salbutamol were studied during wastewater treatment and the changes in their enantiomeric fractions were observed as a result of treatment process. The authors observed that influent was enriched with $R(+)$-atenolol where as the effluent was found racemic.53

Matamoros and co-workers studied the enantioselective degradation of ibuprofen during WWT process and reported that the degradation of ibuprofen depends on the oxidation status of the plant while its degradation was not found enantioselective under anaerobic conditions. ${ }^{54}$ Hühnerfuss and Shah reported that metabolites of ibuprofen i.e. hydroxyibuprofen and carboxyibuprofen were not only found in human body through different enzymatic process but also observed in a STP and in rivers. ${ }^{55}$ Buser et al. reported the occurrence of ibuprofen in river water and observed the more degradation of non-pharmacologically active $R$-enantiomer of ibuprofen. ${ }^{14}$

Commonly, $\beta$-blockers are being used for the treatment of high blood pressure and to treat the heart patients. These compounds act by competitive inhibition of $\beta$-adrenergic receptors in the body. However, atenolol, propranolol and metoprolol are reported as the most widely studied $\beta$-blockers in environmental studies. Most of the researchers have reported about the stereoselective bio-degradation of $\beta$-blockers in aquatic system and during waste water treatment process. However, several authors reported stereoselective bio-

Table 1. Chiral drug enantiomers and their bioactivities.

\begin{tabular}{ll} 
Chiral drug & Enantiomer's bioactivity (property) \\
Ethambutol & (S,S)-form is tuberculostatic agent \\
Ketamine & $(+)$-enantiomer possess stronger anesthetic property \\
\hline Albuterol & (D)-form can provoke airway constriction and (L)-form avoids the side effects \\
Morphine & $(-)$-form has strong analgesic property \\
\hline Propanolol & Only (S)-form possesses the $\beta$-adrenergic blocking activity \\
Propoxyphene & $\alpha$-D-form is analgesic and $\beta$-L-form is anti-tussive \\
\hline Thalidomide & (S)-form possesses the anti-nausea effects and (R)-form causes the \\
Warfarin & malformation of embryos in pregnant woman \\
\hline Penicillamine & (-)-enantiomer is strong anticoagulant agent \\
Dopa & (R)-form is toxic and (S)-form has anti-arthritic activity \\
Non-steroidal anti & (+)-form is Parkinson's disease agent while (D)-form creates side effects \\
inflamatory drugs &
\end{tabular}


logical degradation of $\beta$-blockers during (WWTP) treatment and in the aqueous environment. ${ }^{56,57}$ The enantioselective degradation of three $\beta$-blockers such as metoprolol, atenolol and propranolol have been studied during waste water treatment and reported that it was due to seasonal effect and selectivity of micro organisms having the capability of degradation of the analyte. ${ }^{56}$ Besides this, the authors also reported the different stereoselectivity of different WWTPs.

Stan and Linkerhägner has recognized the presence of clofibric acid abundantly in ground water samples of Berlin city in Germany, which is a metabolite of the lipid regulating agents clofibrate and etofibrate. ${ }^{58}$ Some reports have revealed that few drugs like ibuprofen, bezafibrate, metoprolol have been occurred in the environment i.e. in STP effluent and river water with more than $80 \%$ rate of elimination. ${ }^{59,60}$ Hühnerfuss et al. have reported the enzymatic transformation processes of chiral pharmaceuticals in the aquatic environment. Under this study, the authors have verified the various enzymatic metabolism of ibuprofen and the formation of carboxyibuprofen and hydroxyibuprofen in human body, in biological treatment stage of STP and in river water samples by using enantioselective GC analyses. ${ }^{61}$ Gagnon and Lajeunesse detected the acidic pharmaceutical drugs such as clofibric acid, carbamazepine, diclofenac, ibuprofen and naproxen in large quantity in primary treated effluents i.e. from 77-2384 ng/L. ${ }^{62}$ The detected concentrations of various drugs in inlet and outlet of waste water treatment plants are described in Table 2 and also described the less efficiency of WWTPs for some drugs. ${ }^{63}$

\section{Chiral drug analysis}

The pure enantiomer of any drug or pharmaceutical can be obtained by enantioselective synthesis but this approach is expensive. Generally we get a racemic mixture in a synthesis but the resolution of the enantiomers from a racemate is necessary on preparative scale after the development of a method on analytical scale. Besides this, chiral resolution is not only necessary to control synthesis and enantiomeric purity but for checking the racemization of drug enantiomer and pharmacokinetic study. Despite the presence of some classical methods of chiral separation such as preferential crystallization and enzymatic degradation (biotransformation), some advanced techniques have been developed for this purpose including chromatographic, electrophoretic, biosensor and spectroscopic tools. Electrophoretic method for chiral separation includes its various forms like capillary gel electrophoresis, capillary zone electrophoresis, capillary isotachophoresis etc. On the other hand chromatographic chiral resolution technique has also received the importance through its liquid chromatographic method. Liquid chromatography covers mainly high performance liquid chromatography, capillary electrochromatography, supercritical chromatography, thin layer chromatography etc. Besides this, ultra performance liquid chromatography and ultra high performance liquid chromatography are advanced techniques to fulfil the aim. However, liquid chromatography based chiral methods and chiral products are fast in race at global scale. The most important aspect in chiral resolution by high-performance liquid chromatography is the application of chiral stationary phases such as polysaccharides, cyclodextrins, macrocyclic glycopeptide antibiotics, crown ethers, proteins, Pirkle types and ligand exchangers etc. ${ }^{7}$ Nano liquid chromatographic methods have been developed and very significantly being used in chiral drug analysis in environmental samples. ${ }^{64}$

Gas chromatography with mass spectrometry i.e. GC-MS or tandem mass spectrometry i.e. GC-MS/MS and liquid chromatography with mass spectrometry (LC-MS) or with tandem mass spectrometry (LC-MS/MS) are the advanced analytical and detection methods for the detection of chiral drugs and their enantiomers at nanogram per liter in samples from various environmental matrices. Some scientists have reported these analytical tools for the detection of these compounds in environ- mental samples as given below in Table $3 .^{52,65,66}$ Table 4 shows the occurrence of ibuprofen concentrations in different environment matrices. ${ }^{67-79}$ The chiral drug analysis in environmental samples by chromatographic methods including gas and liquid chromatographic methods takes place through various chiral recognition mechanisms depending on the chiral selectors used. Liquid chromatographic resolution of racemic compounds either pharmaceuticals or agrochemicals have achieved a great reputation in the ground of separation science. ${ }^{5,780-82}$ Chiral Drug analysis on different chiral selectors occurs through some mechanisms like dipole induced dipole, hydrogen, $\pi$ $\pi$ interactions, Vander Waals forces etc. between analyte and chiral selectors depending on the selection of method of analysis and nature of analyte.

\section{Futuristic aspects of chiral drugs}

On the basis of above discussion, it can be said that chiral drugs have become an urgent need of the day due to several important reasons like their improved therapeutic index, less complex pharmacodynamics and pharmacokinetic profile, less drug toxicity, less or nil side effects etc..9,83 But the proper disposal of sewage waste by advanced treatment plants of sufficient efficiencies is necessary to prevent

Table 2. Concentrations of various drugs in $\left(\mathrm{ng} \mathrm{L}^{-1}\right)$ inlet and outlet of waste water treatment plants.

\begin{tabular}{lcc} 
Drug & Before WWIPs (inlet) & After WWIPs (outlet) \\
Ibuprofen & 516 & 266 \\
Propanolol & 290 & 168 \\
\hline Atenolol & 400 & 395 \\
Sotalol & 185 & 167 \\
\hline Ketoprofen & 451 & 318 \\
Naproxen & 99 & 108 \\
\hline Diclofenac & 250 & 215 \\
Acetaminophen & 10,194 & 2102 \\
\hline Clofibrate & 72 & 28 \\
Carbamazepine & 420 & 410 \\
\hline
\end{tabular}

WWTPs, waste water treatment plants.

Table 3. Analytical methods for the detection of chiral drugs in environmental samples.

\begin{tabular}{lr} 
Sr. No. & Analytical method \\
1 & GC-MS or GC-MS/MS without derivatization \\
2 & GC-MS or GC-MS/MS with derivatization \\
\hline 3 & LC-MS or LC-MS/MS \\
\hline GC, gas chromatography; MS/MS, tandem mass spectrometric; LC, liquid chromatography.
\end{tabular}


Table 4. Occurrence of ibuprofen in different environmental matrices of different countries.

\begin{tabular}{lcc} 
Matrices, Country & Concentration & Reference \\
WWE, California, USA & $<0.5 \mathrm{mg} / \mathrm{L}$ & 67 \\
WWE, Romania & $15-774 \mathrm{ng} / \mathrm{L}$ & 68 \\
\hline WWTP effluents, Switzerland & $1.3 \mathrm{mg} / \mathrm{L}$ & 69 \\
STP, Switzerland & $150-2000 \mathrm{ng} / \mathrm{L}$ & 70 \\
\hline Sediment, Germany & $0.4-8 \mathrm{ng} / \mathrm{L}$ & 72 \\
STP influent, Spain & $6 \mathrm{mg} / \mathrm{L}$ & 73 \\
\hline Sewage water, Sweden & $14 \mathrm{ng} / \mathrm{L}$ & 74 \\
Wastewater, Singapore & $0.03-0.08 \mathrm{mg} / \mathrm{L}$ & 75 \\
\hline Wastewater, Carolina, UK & $0.03-0.96 \mathrm{ng} / \mathrm{L}$ & 72 \\
River water, Spain & $3-5 \mathrm{ng} / \mathrm{L}$ & 76 \\
\hline River water, UK & $3 \mathrm{mg} / \mathrm{L}$ & 77 \\
River water, Canada & $<10 \mathrm{ng} / \mathrm{L}$ & 78 \\
\hline River water, Germany & $0.6 \mathrm{ng} / \mathrm{L}$ & 79 \\
River water, USA & $0-34 \mathrm{ng} / \mathrm{L}$ & \\
\hline
\end{tabular}

WWE, waste water effluent; WWTPs, waste water treatment plants; STP, sewage treatment plant.

the introduction of these compounds in to the environment i.e. in soil, water, sediments, etc.

Therefore, it will not be an overstatement regarding chiral drugs that these drugs will receive a special attention by scientists and researchers but also doctors considering their significance and will prefer chiral drugs instead of racemates.

\section{Conclusions}

Research and Development work for chiral drug studies through educational research institutes, pharma industries and municipal corporations can be done to achieve the goal. Besides, rapid chiral drug analysis can be achieved by advanced online nano level technologies. Finally, the dosage potential of a medicine can be reduced by adopting the concept of pure enantiomer for human welfare. Consequently, it has become an urgent need to analyze the chiral drug enantiomers and xenobiotics in various environmental samples like water, soil or sediments to know the exact metabolism and fate of these compounds.

\section{Research highlights}

- Nature and bioactivities of chiral drugs has been described along with global market and strategies.

- Occurrence of chiral drugs in environmental matrices has been reviewed.

- Analysis of chiral compounds in environmental samples has been described with their futuristic aspects.
11. Winkler M, Lawrence JR, Neu TR. Selective degradation of ibuprofen and clofibric acid in two model river biofilm systems. Water Res 2001;35:3197.

12. Ali I, Aboul-Enein HY, Singh P, Sharma B. Chiral analyses of ibuprofen residues in water and sediment. Anal Lett 2009;42: 1747-60.

13. Kümmerer K, Al-Ahmadi A, Bertram B, Wiebler M. Biodegradability of antineoplastic compounds in screening tests: Influence of glucosidation and of stere0chemistry. Chemosphere 2000;40:767-73.

14. Buser HR, Poigner T, Muller MD. Occurrence and environmental behavior of chiral pharmaceutical drug ibuprofen in surface waters and in wastewater. Environ Sci Technol 1999;33:2529-35.

15. Mahmoud WM, Trautwein C, Leder C, Kümmerer K. Aquatic photochemistry, abiotic and aerobic biodegradability of thalidomide: identification of stable transformation products by LC-UV-MS(n). Sci Total Environ 2013;463-464:140-50.

16. US Environment Protection Agency (EPA). Literature review of contaminants in livestock and poultry manure and implications for water quality. Office of Water (4304T); EPA 820-R-13-002; July 2013. Available from: http://water.epa.gov/scitech/cec/ upload/Literature-Review-of-Contaminantsin-Livestock-and-Poultry-Manure-andImplications-for-Water-Quality.pdf Accessed: 18/03/2014.

17. Animal and Plant Health Inspection Service/United States Department of Agriculture (APHIS/USDA). Highlights of health and management practices on breeder chicken farms in the United States, 2010. Info Sheet; November 2011. Available from: http://www.aphis.usda. gov/animal_health/nahms/poultry/downloads/poultry10/Poultry10_is_Breeder_hig hlights.pdf

18. Kasprzyk-Hordern B, Baker DR. Enantiomeric profiling of chiral drugs in wastewater and receiving waters. Environ Sci Technol 2012;46:1681-91.

19. Carballa M, Omil F, Lema JM, Llompart M, García-Jares C, Rodríguez I, et al. Behavior of pharmaceuticals, cosmetics and hormones in a sewage treatment plant. Water Res 2004;38:2918-26.

20. Halling-Sørensen B, Nors Nielsen S, Lanzky PF, Ingerslev F, Holten Lutzhoft HC, Jorgensen SE. Occurrence, fate and effects of pharmaceutical substances in the environment-A review. Chemosphere 1998;36: 357-93.

21. BCC Research. Global markets for chiral technology - Focus on emerging markets. Report: BI0103A; April 2012. Available from: http://www.bccresearch.com/marketresearch/biotechnology/chiral-products-
9. Tucker GT. Chiral switches. Lancet 2000;355:1085-87.

10. Francotte E, Lindner W. Chirality in drug research. Vol. 32. Weinheim: Wiley VCH; 2006. 
technology-global-markets-bio012f.html

22. McConalthy J, Owens MJ. Sterochemistry in drug action. J Clin Psychiatr Primary Care Compan 2003;5:70-3.

23. Lin JH, AYH Lu. Role of pharmacokinetics and metabolism in drug discovery and development. Pharmacol Rev 1997;49:40349.

24. Li B, Haynie DT. Chiral drug separation. In: Lee S, ed. Encyclopedia of chemical processing. Vol. 1. New York, NY: Taylor \& Francis; 2006. pp 449-58.

25. Hegeman WJM, Laane WPJ. Enantiomeric enrichment of chiral pesticides in the environment. Rev Environ Contam Toxicol 2002;173:85-116.

26. Fent K, Weston AA, Caminada D. Ecotoxicology of human pharmaceuticals. Aquatic Toxicol 2006;76:122-59.

27. Carlsson C, Johansson AK, Alvan G, Bergman K, Kuhler T. Are pharmaceuticals potent environmental pollutants? Part I: Environmental risk assessments of selected active pharmaceutical ingredients. Sci Total Environ 2006;364:67-87.

28. Kasprzyk-Hordern B, Dinsdale RM, Guwy AJ. The removal of pharmaceuticals, personal care products, endocrine disruptors and illicit drugs during wastewater treatment and its impact on the quality of receiving waters. Water Res 2009;43:36380.

29. van Nuijs LN, Pecceu B, Theunis L, Dubois N, Charlier C, Jorens PG, et al. Erratum to "Cocaine and metabolites in waste and surface water across Belgium". [Environmental Pollution 157(2009), 123-129], Environ Poll 2009;157:1968-69.

30. Castiglioni S, Bagnati R, Calamari D, Fanelli R, Zuccato E. A multiresidue analytical method using solid-phase extraction and high-pressure liquid chromatography tandem mass spectrometry to measure pharmaceuticals of different therapeutic classes in urban wastewaters. J Chromatogr A 2005;1092:206-15.

31. Richardson SD, Ternes TA. Water analysis: emerging contaminants and current issues. Anal Chem 2005;77:3807-38.

32. Sanderson H, Thomsen M. Comparative analysis of pharmaceuticals versus industrial chemicals acute aquatic toxicity classification according to the United Nations classification system for chemicals. Assessment of the (Q)SAR predictability of pharmaceuticals acute aquatic toxicity and their predominant acute toxic modeof-action, Toxicol Lett 2009;187;84-93.

33. Ali I, Jain CK. Groundwater contamination and health hazards by some of the most commonly used pesticides. Curr Sci 1998;75:1011.

34. Kolpin DW, Kalkhoff SJ, Goolsby DA, Sneck-Fahrer DA, Thurman EM.
Occurrence of Selected Herbicides and Herbicide Degradation Products in Iowa's Ground Water. Ground Water 1997;35:679.

35. Hutta M., Rybar I, Chalanyova M. Liquid chromatographic method development for determination of fungicide epoxiconazole enantiomers by achiral and chiral column switching technique in water and soil. J Chromatogr A 2002;959:143-52.

36. Leone AD, Amato S, Falconer RL. Emission of chiral organochlorine pesticides from agricultural soils in the Cornbelt Region of the U.S. Environ Sci Technol 2001;35:459296.

37. Vetter W, Bartha R, Stern G, Tomy G. Enantioselective determination of two persistent chlorobornane congeners in sediment from a toxaphene-treated yukon lake. Environ Toxicol Chem 1999;18:277581.

38. Wong CS, Garrison AW, Foreman WT. enantiomeric composition of chiral polychlorinated biphenyl atropisomers in aquatic bed sediment. Environ Sci Technol 2001;35:33-9.

39. Pylypiw HM, Naughton E, Hankin L. DDT persists in soil: uptake by squash plants. $\mathrm{J}$ Dairy Food Environ Sanit 1991;11:200-1.

40. Mattina MJIM, Iannucci-Berger W, Dykes L. Chlordane uptake and its translocation in food crops. J Agric Food Chem 2000;48:1909-15.

41. Hernando MD, Mezcua M, Fernandez-Alba AR, Barcelo D. Environmental risk assessment of pharmaceutical residues in wastewater effluents, surface waters and sediments. Talanta 2006;69:334-42.

42. Lishman L, Smyth SA, Sarafin K, Kleywegt S, Toito J, Peart T, et al. Occurrence and reductions of pharmaceuticals and personal care products and estrogens by municipal wastewater treatment plants in Ontario, Canada. Sci Total Environ 2006;367:544-58.

43. Kummerer K (ed.). Pharmaceuticals in the environment, 2nd ed. Berlin, Heidelberg, New-York: Springer; 2004.

44. Gentili A. Determination of non-steroidal anti-inflammatory drugs in environmental samples by chromatographic and electrophoretic techniques. Anal Bioanal Chem 2007;387:1185-202.

45. Miège $\mathrm{C}$, Choubert JM, Ribeiro L, Eusène M, Coquery M. Fate of pharmaceuticals and personal care products in wastewater treatment plants - Conception of a database and first results. Environ Pollut 2009;157:1721-26.

46. Löffler D, Römbke J, Meller M, Ternes TA. Environmental fate of pharmaceuticals in water/sediment systems. Environ Sci Technol 2005;39:5209-18.

47. Lajeunesse A, Gagnon C, Sauvé S. Determination of antidepressants and their $\mathrm{N}$-desmethyl metabolites in raw sewage and wastewater using solid-phase extraction and liquid chromatography-tandem mass spectrometry. Anal Chem 2008;80:5325-33.

48. Heberer T. Occurrence, fate, and removal of pharmaceutical residues in the aquatic environment: a review of recent research data. Toxicol Lett 2002;131:5-17.

49. Nikolaou A, Lofrano G. Detection of transformation products of emerging contaminants (Chapter 2). In: Lofrano G, ed. Green technologies for wastewater treatment Energy recovery and emerging compounds removal. Berlin: Springer; 2012. pp 19-29.

50. World Health Organization (WHO). Pharmaceuticals in drinking water. Geneva: WHO; 2012. Available from: https://extranet.who.int/iris/restricted/bitstream/10665/44630/1/9789241502085_en g.pdf

51. Albero B, Pérez RA, Sánchez-Brunete C, Tadeo JL. Occurrence and analysis of parabens in municipal sewage sludge from wastewater treatment plants in Madrid (Spain). J Hazard Mat 2012;239-240:48-55.

52. Fatta D, Nikolaou A, Achilleos A, Meric S. Analytical methods for tracing pharmaceutical residues in water and wastewater. Trends Anal Chem 2007;26:515-33.

53. MacLeod SL, Sudhir P, Wong CS. Stereoisomer analysis of wastewaterderived $\beta$-blockers, selective serotonin reuptake inhibitors, and salbutamol by highperformance liquid chromatography-tandem mass spectrometry. J Chromatogr A 2007;1170:23-33.

54. Matamoros V, Hijosa M, Bayona JM. Assessment of the pharmaceutical active compounds removal in wastewater treatment systems at enantiomeric level. Chemosphere 2009;75:200-05.

55. Huhnerfuss H, Shah MR. Enantioselective chromatography - a powerful tool for the discrimination of biotic and abiotic transformation processes of chiral environmental pollutants. J Chromatogr A 2009;1216: 481-502.

56. Nikolai LN, McClure EL, MacLeod SL, Wong CS. Stereoisomer quantification of the -blocker drugs atenolol, metoprolol, and propranolol in wastewaters by chiral high-performance liquid chromatography-tandem mass spectrometry. J Chromatogr A 2006;1131:103-9.

57. Fono LJ, Sedlak DL. Use of the chiral pharmaceutical propranolol to identify sewage discharges into surface waters. Environ Sci Technol 2005;39:9244-52.

58. Stan HJ, Linkerhägner M. Identifizierung von 2-(4-Chlorphenoxy)-2-methylpropionsäure im Grundwasser mittels KapillarGaschromatographie mit Atomemissionsdetektion und Massenspe- 
ktrometrie [Identification of 2-(4chlorophenoxy)-2-methyl-propionic acid in ground water using capillary-gas chromatography with atomic emission detection and mass spectrometry]. Vom Wasser 1992;79:75-88.

59. Ternes TA, Hirsch R. occurrence and behavior of $\mathrm{x}$-ray contrast media in sewage facilities and the aquatic environment. Environm Sci Technol 2000;34:2741-8.

60. Ternes TA. Occurrence of drugs in German sewage treatment plants and rivers. Water Res 1998;32:3245.

61. Hühnerfuss H, Selke S, Kallenborn R, Kuhlmann J, Weigel S. Enzymatic transformation of chiral pharmaceuticals in the environment as revealed by enantioselective chromatography, Organohalogen Compounds. 2006;68:17-20.

62. Gagnon C, Lajeunesse A. Low removal of acidic and hydrophilic pharmaceutical products by various types of municipal wastewater treatment plants. J Xenobiot 2012;2:13-7.

63. Petrovic M, Hernando MD, Díaz-Cruz MS, Barceló D. Liquid chromatography- tandem mass spectrometry for the analysis of pharmaceutical residues in environmental samples: a review. J Chromatogr A 2005;1067:1-14.

64. Ali I, Aboul-Enein HY, Gupta VK. Nano chromatography and capillary electrophoresis: pharmaceutical and environmental analyses. Hoboken, NJ:Wiley \& Sons; 2009.

65. Albero B, Sánchez-Brunete C, Miguel E, Pérez RA, Tadeo JL. Analysis of naturaloccurring and synthetic sexual hormones in sludge-amended soils by matrix solidphase dispersion and isotope dilution gas chromatography-tandem mass spectrometry. J Chromatogr A 2013;1283:39-45.

66. Fatta-Kassinos D, Meric S, Nikolaou A. Pharmaceutical residues in environmental waters and wastewater: current state of knowledge and future research. Anal
Bioanal Chem 2011;399:251-75.

67. Gross B, Montgomery-Brown J, Naumann A, Reinhard M. Occurrence and fate of pharmaceuticals and alkyl phenol ethoxylate metabolites in an effluent-dominated river and wetland. Environ Toxicol Chem 2004;23:2074-83.

68. Moldovan Z, Schmutzer G, Tusa F, Calin R, Alder AC. An overview of pharmaceuticals and personal care products contamination along the River Somes watershed, Romania. J Environ Monit 2007;9:986-93.

69. Tixier C, Singer HP, Oellers S, Müller SR. Occurrence and fate of carbamazepine, clofibric acid, diclofenac, ibuprofen, ketoprofen, and naproxen in surface waters. Environ Sci Technol 2003;37:1061-8.

70. Tauxe-Wuersch A, De Alencastro LF, Grandjean D, Tarradellas J. Occurrence of several acidic drugs in sewage treatment plants in Switzerland and risk assessment. Water Res 2005;39:1761-2.

71. Löffler D, Ternes TA. Determination of acidic pharmaceuticals, antibiotics, and ivermection in river sediment using liquid chromatography-tandem mass spectrometry. J Chromatogr A 2003;1021:133-44.

72. Pedrouzo M, Reverte S, Borrull F, Pocurull E, Marce RM. Pharmaceutical determination in surface and waste waters using high-performance liquid chromatography (electrospray) - mass spectrometry. J Sep Sci 2007;30:297-303.

73. Zorita S, Barri T, Mathiasson L. A novel hollow-fibre microporous membrane liquid-liquid extraction for determination of free 4-isobutylacetophenone concentration at ultra trace level in environmental aqueous samples. J Chromatogr A 2007; 1157:30-7.

74. Basheer C, Chong HG, Hii TM, Lee HK. Application of porous membrane-protected micro-solid-phase extraction combined with HPLC for the analysis of acidic drugs in waste water. Anal Chem 2007;79:684550 .
75. Nebot C, Gibb SW, Boyd KG. Quantification of human pharmaceuticals in water samples by high performance liquid chromatography-tandem mass spectrometry. Anal Chim Acta 2007;598:87-94.

76. Bound JP, Voulvoulis N. Predicted and measured concentrations for selected pharmaceuticals in UK rivers: Implications for risk assessment. Water Res 2006;40:2885-92.

77. Yu Z, Peldszus S, Huck PM. Optimizing gas chromatographic - mass spectrometric analysis of selected pharmaceuticals and endocrine disrupting substances in water using factorial experimental design. J Chromatogr A 2007;1148:65-77.

78. Winkler M, Lawrence JR, Neu TR. Selective degradation of ibuprofen and clofibric acid in two model river biofilm systems. Water Res 2001;35:3197-205.

79. Zhang S, Zhang Q, Darisaw S, Ehie 0, Wang G. Simutaneous quantification of polycyclic aromatic hydrocarbons (PAHs), polychlorinated biphenyls (PCBs), and pharmaceuiticals and personal care products (PPCBs) in Mississippi River water, in New Orleans, Louisiana, USA. Chemosphere 2007;66:1057-69.

80. Aboul-Enein HY, Wainer IW. The impact of stereochemistry on drugs development and use. Vol. 142. New York, NY: Wiley; 1997.

81. Ali I, Aboul-Enein HY, Gaitonde VD, Singh P, Rawat MSM, Sharma B. Chiral separations of imidazole antifungal drugs on AmyCoat RP column in HPLC. Chromatographia 2009;70:223-7.

82. Sharma B, Tyagi S, Singh R, Singh P. Monitoring of organochlorine pesticides in fresh water samples by gas chromatography and bioremediation approaches. Natl Acad Sci Lett 2012;35:401-13.

83. Burke D, Henderson DJ. Chirality: a blueprint for the future. Br J Anesth 2002; 88:563-76. 